\title{
Rubinstein Taybi Syndrome with Hepatic Hemangioma
}

\author{
U.M. Sahiner S. Senel N. Erkek C. Karacan A. Yoney \\ Department of Pediatrics, Dr. Sami Ulus Children's Hospital, Ankara, Turkey
}

\section{Key Words}

Rubinstein Taybi syndrome • Hepatic hemangioma •

Cutaneous hemangioma

\begin{abstract}
Objective: It was the aim of our study to present a case of Rubinstein Taybi syndome (RTS) associated with hepatic hemangioma. Clinical Presentation and Intervention: A 6.5-year-old boy was diagnosed with RTS. He had large areas of cutaneous capillary hemangiomas. Radiological examination revealed a hepatic hemangioma. A multidisciplinary follow-up program was commenced and hepatic ultrasound examinations were performed periodically. No progression and complication have since occurred. Conclusion: This case shows an association between RTS and hepatic hemangio$\mathrm{ma}$, and hence, we recommend regular hepatic ultrasound examination when RTS is suspected or diagnosed.
\end{abstract}

Copyright $\odot 2009$ S. Karger AG, Basel

\section{Introduction}

Rubinstein Taybi syndrome (RTS) is a rare genetic disorder that is characterized by typical facies, short stature, severe learning difficulties and broad toes and thumbs [1]. Cardiac, neurologic, ocular, skeletal, gastrointestinal, renal, genitourinary and cutaneous abnormalities such as hypertrichosis, capillary hemangiomas, follicular keratosis and keloids may also occur [1-3]. The incidence of the syndrome has been estimated to be 1 in 300,000 newborns [4]. Since 1963, when Rubinstein and Taybi described this rare medical disorder, more than 200 different reports have appeared in the literature [4]. However, hepatic hemangioma has not been reported with RTS. We herein describe a patient with RTS associated with hepatic hemangioma.

\section{Case Report}

A 6.5-year-old boy was referred to our hospital with complaints of recurrent respiratory tract infections. He was the second child of healthy, non-consanguineous parents. Family history was unremarkable and pregnancy uneventful. He had had surgeries for nasolacrimal duct obstruction, strabismus and bilateral cryptorchidism during infancy. On physical examination, his head circumference, weight and height measures were below the 3 rd percentile. He was mentally challenged. He had characteristic signs of RTS, including a prominent forehead with high hairline, an asymmetric antimongoloid slant of the palpebral fissures, dysplastic ears, hypertelorism, arched and long eyebrows, a convex beaked profile of the nose, columella below the alae nasi, maxillary hypoplasia, high-arched and narrow palate, incorrectly positioned and crowded teeth. He had broad, short thumbs and great toes; syndactily was present in the lower extremities. A huge capillary hemangioma was located at the back and multiple small hemangiomas scattered over the thoracic region. An ophthalmologic examination was normal except for infantile exotropia and

\section{KARGER}

Fax +4161306 1234

E-Mail karger@karger.ch

www.karger.com
(C) 2009 S. Karger AG, Basel

1011-7571/09/0182-0162\$26.00/0

Accessible online at:

www.karger.com/mpp
Dr. Umit Murat Sahiner

Dr. Sami Ulus Children's Hospital, Department of Pediatrics

TR-06080 Ankara (Turkey)

Tel. +90 312305 6252, Fax +90 3123170353

E-Mail umsahner@yahoo.com 
a subconjunctival cystic appearance on the left eye secondary to surgery. Laboratory investigations including blood count, biochemistry, urinalysis, thyroid hormone levels and immunoglobulins were normal. Vertebra X-rays showed spina bifida at the level of the 5th lumbar and 1st sacral vertebrae. Abdominal ultrasonography (US) revealed a $7 \times 10 \mathrm{~mm}$ hepatic hemangioma in the left lobe of the liver near the falciform ligament (fig. 1). Renal US showed few stones, the largest $7 \mathrm{~mm}$ in diameter. Electrocardiogram and telecardiography were normal. Mitral valve prolapse (MVP) was shown on echocardiography. Cranial magnetic resonance imaging (MRI) revealed corpus callosum agenesis and choroidal cysts. Gastroesophageal reflux was shown on reflux scintigraphy. The karyotype was normal. He was diagnosed as RTS according to the characteristic clinical features of the syndrome.

A multidisciplinary follow-up program was commenced with the pediatric gastroenterology, cardiology, orthopedics, ophtalmology and neurology departments. He was admitted to a special education program for his disabilities. Serial hepatic US examinations were done during follow-up.

\section{Discussion}

Molecular mutations and microdeletions of chromosome 16p13.3 have been shown in some patients with RTS, but the diagnosis of RTS is made primarily by the clinical features as mutational analysis is not always positive for a gene deletion [2-5]. We diagnosed our patient according to the characteristic clinical features.

It is important to consider that cutaneous hemangiomas may be a risk factor for internal hemangiomas, with the liver being the most common site. A recent study showed that $23 \%$ of patients with 6 or more small or 1 large $(\geq 5 \mathrm{~cm})$ cutaneous hemangioma had hepatic hemangioma [6], as in our case. Although computerized tomography and MRI should be used to define the extent of the endangering lesions [6], we performed neither a computerized tomography nor an MRI because we did not want to give unnecessary radiation or sedation to the child, and much more importantly, adequate diagnostic information had been obtained using serial US.

Hepatic hemangiomas, though histologically benign and clinically silent, may be associated with significant complications such as rapid growth, spontaneous or traumatic rupture, consumption coagulopathy, abnormal liver function tests and congestive heart failure [7]. Cardiac abnormalities occur frequently in RTS. Patent ductus arteriosus, ventricular septal defect and atrial septal defect are most commonly reported. We found MVP in our patient. Review of the medical literature shows only 1 report about a mitral valve [8]. MVP is a collagen tissue dysplasia with autosomal dominant inheritance [9]. In RTS, transcriptional coactivator $\mathrm{P} 300$, a nuclear protein which

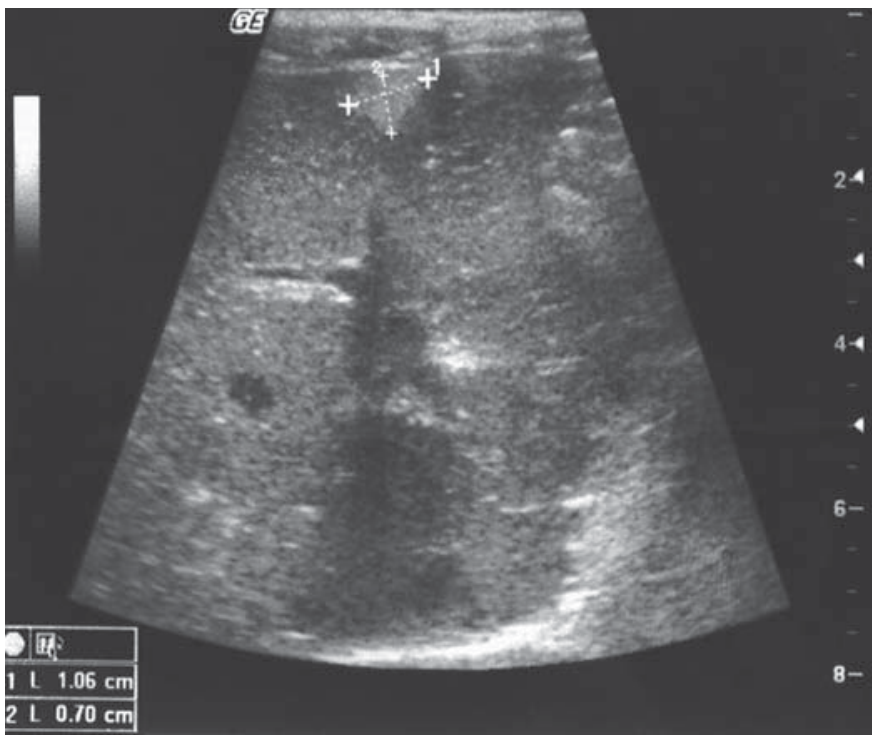

Fig. 1. Abdominal US of the patient revealed a hepatic hemangioma sized $7 \times 10 \mathrm{~mm}$ in the left lobe of the liver near the falciform ligament.

plays a role in the regulation of collagen synthesis, has abnormal function [10]. It may suggest that this cardiac lesion is a less common association of RTS, but further studies are needed.

Our patient also had corpus callosum agenesis as previously reported [11], but more clinical and molecular information is needed in order to establish if it is a less common association of this syndrome or if it is coincidental.

Gastroesophageal reflux and feeding problems are common in RTS and can lead to inadequate intake of calories $[2,3]$. Our patient also had feeding difficulties, and hence, a specific calorie-rich diet was prepared for him.

Genitourinary anomalies including renal stones have been reported previously [2]. Our patient had multiple renal stones, but more data are needed to explain the mechanism of renal stones in RTS and establish an association between renal stones and the syndrome [2, 3].

Children with RTS have additional health concerns that require a multidisciplinary follow-up monitoring.

\section{Conclusion}

This case shows an association between RTS and hepatic hemangioma. Therefore, we recommend regular hepatic US examination when RTS is suspected or diagnosed. 


\section{References}

1 Rubinstein JH, Taybi H: Broad thumbs and toes and facial abnormalities. Am J Dis Child 1963;105:588-608.

$\checkmark 2$ Wiley S, Swayne S, Rubinstein JH, Lanphear NE, Stevens CA: Rubinstein Taybi syndrome medical guidelines. Am J Med Genet 2003; 119A:101-110.

>3 Hennekam RC, Van den Boogaard MJ, Sibbles J, Van Spijker HG: Rubinstein Taybi syndrome in the Netherlands. Am J Med Genet Suppl 1990;6:17-29.

$\checkmark 4$ Freitas NM, Imbronito AV, La Scala CS, Lotufo RF, Pustiglioni FE: Periodontal disease in a Rubinstein-Taybi syndrome patient: case report. Int J Paediatr Dent 2006;16:292296. $\checkmark 5$ Hennekam RC, Tilanus M, Hamel BC, Voshart-van Heeren H, Mariman EC, van Beersum SE, van den Boogaard MT, Breuning $\mathrm{MH}$ : Deletion at chromosome $16 \mathrm{p} 13.3$ as a cause of Rubinstein Taybi syndrome: clinical aspects. Am J Hum Genet 1993;52:255262.

6 Hughes JA, Hill V, Patel K, Syed S, Harper J, De Bruyn R: Cutaneous haemangioma: prevalence and sonographic characteristics of associated hepatic haemangioma. Clin Radiol 2004;59:273-280.

7 Gourgiotis S, Moustafellos P, Zavos A, Dimopoulos N, Vericouki C, Hadjiyannakis E: Surgical treatment of hepatic hemangiomas: a 15 year experience. ANZ J Surg 2006;76: $792-795$.
-8 Kanjilal D, Basir MA, Verma RS, Rajegowda BK, Lala R, Nagaraj A: New dysmorphic features in Rubinstein-Taybi syndrome. J Med Genet 1992;29:669-670.

9 Bobkowski W, Nowak A, Durlach J: The importance of magnesium status in the pathophysiology of mitral valve prolapse. Magnes Res 2005;18:35-52.

10 Ghosh AK, Varga J: The transcriptional coactivator and acetyltransferase p300 in fibroblast biology and fibrosis. J Cell Physiol 2007;213:663-671.

11 Guion-Almeida ML, Richieri-Costa A: Callosal agenesis, iris coloboma, and megacolon in a Brazilian boy with Rubinstein-Taybi syndrome. Am J Med Genet 1992;43:929931. 